the Stomach and their Surgical Treatment," p.189 (Baillière, Tindall, and Cox, 1901).

I am, Sirs, yours faithfully,

Park-crescent, W., August 8th, 1903. A. W. MAYo Robson.

\section{THE TRINIDAD EPIDEMIC.}

\section{To the Editors of THE LANCET.}

SIRS, - With reference to the controversy regarding the true nature of the epidemic prevailing in certain parts of the West Indies and alleged in many of the islands to be chicken-pox, I inoculated a monkey with variolous matter taken from a case of so-called varicella at the Colonial Hospital. Four insertions were made by a series of cross scratches as in ordinary vaccination, two being with matter from vesicles six days old and two from vesicles of the seventh day. Four days later there was a distinct raised papule surrounded by a zone of inflammation at the site of each insertion. About the sixth day (the day on which the photograph was taken) vesiculation, though not very perfect, was apparent and scabbing commenced. As it is well agreed that chicken-pox is not an inoculable disease it is to be hoped that in view of the success of this simple experiment the last has been heard, among medical men, at any rate, of the term "varicella" in connexion with the present outbreak of small-pox in the West Indies.

I am, Sirs, yours faithfully,

GEORGE H. MASSON, M.D., B.Sc., M.R.C.P. Edin, Port of Spain, Trinidad B.W.I., July 31st, 1903.

** Dr. Masson incloses a photograph of the monkey showing the vesicles very clearly.-ED. L.

\section{THE ADMINISTRATION OF SOMNOFORM.}

\section{To the Editors of THE LANCET.}

Sirs,--In The LanceT of August 1st, p. 323, appeared a description of yet another excellent apparatus for the administration of somnoform. I have found the following plan so simple and to work so well that it appears to me that no special apparatus is required. I take the ordinary Clover's bag, such as every practitioner who is in the habit of giving anæsthetics must possess, and fit it directly on to an ordinary rubber face piece. The latter is lined with wool, leaving, however, the opening into the bag quite free. On this wool the somnoform is syringed and administered in the usual way. The wool lining keeps perfectly in place without any spring such as is required for lint; moreover, it absorbs the somnoform well and is readily removed and replaced. About from three-quarters to twothirds of the dose marked on the bottle is ample, as a rule, for an anæsthesia of three minutes.

I am, Sirs, yours faithfully,

W. Bernard Secretan, M.B. Lond., F.R.C.S. Eng. Leeds, August 10th, 1903.

\section{OBSERVATIONS ON MASTICATION.}

To the Eators of THE LANCET.

SIRs,-For some few years I have been looking forward to the time when physicians would seriously consider the muchneglected subject of mastication. It was therefore with great pleasure that I read Dr. H. Campbell's recent communications. He has certainly presented arguments which strongly support his contentions, while at the same time he has made a very grave indictment on current ideas of correct feeding. The subject is at the present moment being forced upon us in other ways, for the cry has been raised that the national physique is degenerating. This has arisen from the condition of the men who have presented themselves for enlistment in the army. Among other things we find that a large and increasing percentage have been rejected on account of the shockingly defective state of their teeth. Unfortunately the evil does not end here, for in such cases the mouth becomes a receiving and distributing centre for disease, instead of acting with the stomach as it should, as a veritable death-trap for almost every pathogenic microorganism which enters it. If the Royal Commission which is likely to inquire into the degeneracy of the national physique would only direct attention to the physical properties of the food and carefully consider the ultimate effects of the pap-feeding of children they would confer an incalculable benefit on suffering humanity.

Many have probably observed that the mortality has been increasing from those very diseases which are directly or indirectly attributable to improper feeding - "the deathrates from anæmia, from rickets, and from diarrhoea show an increase"-and this in spite of the facts that we have now a relatively more abundant and varied supply of foods than any previous generation, that we have in general greatly improved hygienic and sanitary conditions, and that there is a diminished birth-rate, so that parents can give more individual care and attention to their children.

Upon what physiological principles are "bread well soaked" in milk and the like advocated? Have children neither teeth nor salivary glands? Is it not preferable to let them soak their bread in saliva in the mouth? Is there any reason for advocating food which neither stimulates the movements of the jaws, nor of the stomach, nor of the intestines, but only tends to lodge, to ferment, to derange the normal secretions, and to give rise to a continuous supply of objectionable products of decomposition? Surely the time has come for a crusade against the soft, "refined" food of the present day. It is within the power of the medical profession to reduce rather than to increase the $\mathrm{suffering}$ and mortality from this cause. I am, Sirs, yours faithfully,

Wimpole-street, W., August 9th, $1903 . \quad$ J. SIM WALLACE.

\section{THE MOTOR-CAR BILL.}

\section{To the Editors of THE LANCET.}

SIRS, - It is with sincere sorrow that one reads " your annotation on the above Bill in THE LANCET of August 8th, p. 415. Since the days "when Cooper's nevvy cut for stone" THE LANCET has always been in the forefront of liberal progress, so that it gave one quite an unpleasant shock to read the old-fashioned ideas expressed in the annotation. I have driven a motor-car for five years in my work and for my pleasure, and can claim to be one of the first medical motor drivers in this country, but there are now very many practitioners using the new vehicle with advantage to themselves and to their patients. May I therefore be allowed to point out one or two matters in which your remarks are open to question?

You say, "Our present highways were laid out for horse traffic ...... and if a motor-car goes faster than 15 or 18 miles per hour the road is being used" for unsuitable purposes. Now this speed is practically slow for a car or even more so for a motor bicycle (which scores of medical men are using daily), and yet it is clear to every unprejudiced person that a car or cycle at this speed is more safe on a high-road than a four-in-hand and is infinitely more under control, for one chief reason that there is only one brain concerned in driving a car. But is the progress of locomotion to stand still because the roads are old-fashioned? Surely the obvious thing is to improve the roads, as, indeed, followed the use of bicycles. Motor-cars are per se no more dangerous to traffic than any other form of vehicle, and a motor-car driver is a good deal more careful than a coachman or butcher-boy driving horses ; in the motor the driver is usually driving his own car which has cost him from $£ 200$ to $£ 1500$ and he is not particularly anxious to smash it and himself up by reckless driving, knowing also that he gets no sympathy if he does, whereas the horse driver can be drunk or incapable and if an accident happens "the horse took fright and got beyond control and no blame attached to anyone."

Your annotation says that the cars "cut up the roads." What road is ever so soft as to be cut up by pneumatic or even solid rubber tyres? Why even a private gravel drive is untouched by a motor-car, while a rough hollow is always in the centre where the horses' feet cut up the ground. Again, is there no dust on the road till a car comes? Does no dust arise when a four-in-hand drives along? If the dust is intolerable it shows that the road is badly made and kept and the obvious conclusion is that the roads want modernising to cope with newer methods of locomotion than the "one-hoss shay." As to smell, I find horses quite as offensive as motors ; if they are not, why do people insist on the stables being as far as possible from a house? The psychology of the present opposition to motor-cars is precisely the same as that made against the making of railways and, as I well remember, against eyclists when I used to cycle in the "seventies" and early "eighties." Opposition has been the lot of every machine of new principle introduced-the spinning-wheels, power-looms, saw-grinding machinery, railway trains, steamers, bicycles, and now 